\title{
Modernisation of a Control Cabinet Production Process using Multicriteria OPTIMIZATION LOGIC AND AUGMENTED REALITY
}

\author{
Vladimir N. Khokhlovsky, Vitaly S. Oleynikov, Dmitry Kostenko, \\ Vadim A. Onufriev, Vyacheslav V. Potekhin \\ Peter the Great St. Petersburg Polytechnic University
}
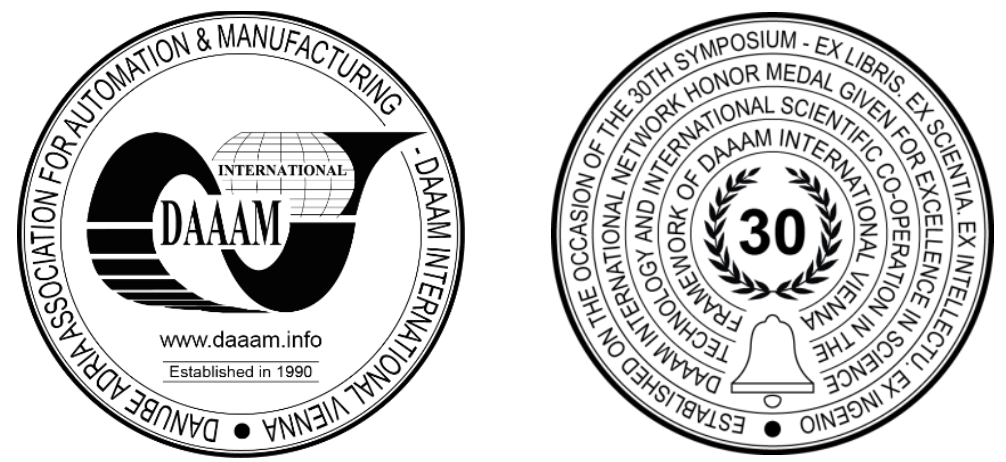

This Publication has to be referred as: Khokhlovskiy, V[ladimir]; Oleynikov, V[italy]; Kostenko, D[mitry]; Onufriev, V[adim] \& Potekhin, V[yacheslav] (2019). Modernisation of a Production Process Using Multicriteria Optimisation Logic and Augmented Reality, Proceedings of the 30th DAAAM International Symposium, pp.0500-0507, B. Katalinic (Ed.), Published by DAAAM International, ISBN 978-3-902734-22-8, ISSN 1726-9679, Vienna, Austria

DOI: $10.2507 / 30$ th.daaam.proceedings.067

\begin{abstract}
This paper describes modernisation of a production process using multicriteria optimisation logic and Augmented Reality enabled hardware. The process is being decomposed and viewed as a hierarchy of embedded sub-processes. Key performance indicators are extracted and evaluated, thus allowing to systematise sources of influence. After the multicriteria optimisation pass is finished, a new intelligent control system containing both soft- and hardware bits is introduced. Its designation is to manage technological process more effectively, lower human resources involvement and increase the process' overall ergonomics.
\end{abstract}

Keywords: Multicriteria optimization; Augmented reality; Intelligent control system; Cyber-Physical Systems.

\section{Introduction}

Complex process modernisation is a well-known task that has been described in precedent works. In paper [1] authors represent a general approach based on data mining and modelling a business process based on machine learning from the extracted data. In order to model or optimize a process, it is important to figure out the most import production factors, as authors of [2] did in their work. They are using statistical methods to optimise a production process using selected process parameters. Important parameters selection can also be done using a system of Key Performance Indicators (KPIs) as described in [3]. The work follows a process of KPI-based production routine optimisation. In paper [4] authors include Pareto optimisation technique to allow for multicriteria production optimisation. The work [5] focuses on researching different methods of optimisation and evaluating their strong and weak sides.

Goal of this paper is to describe an optimization approach [6] for a control cabinet production process. We are viewing the process of a control cabinet assembly and looking for possibilities to automate its steps, to lessen the amount of time consumed, lessen the room for error of an assembly worker and lower the assembly worker qualification requirement. 
In order to grant it, a hierarchic system of KPIs [7] is proposed. The system is to be accounted for when evaluating both standalone technological and business processes, that embody technological processes or communicate with them. Because the KPI system contains inner contradictions (for example, a cost effectiveness requirement contradicts the highest quality requirement), this paper includes multicriteria optimisation methods [8],[9] usage to select the most important performance indicators. The aforementioned analysis is represented using UML models [10]. After the technological process analysis is done, alteration proposals are made. These include not only the assembly per se, but also control cabinet designing stage and assembly worker's working place hardware and software.

\section{Assembly process review}

Modernisation of the control cabinets production process consists of gradual advancement of its existing stages. The process itself is based on transitions between the states seen on figure 1 .

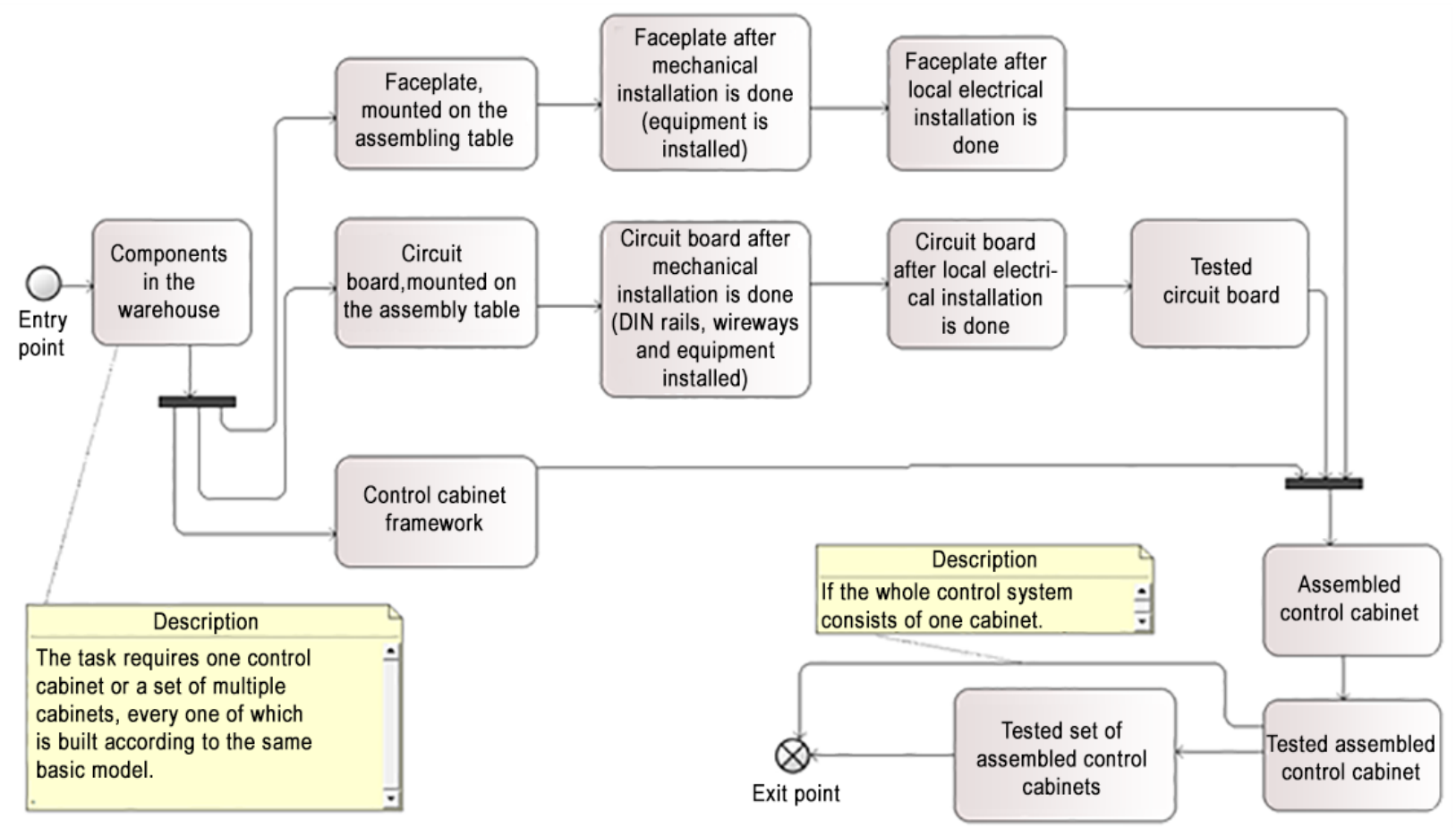

Fig. 1. General model of the control cabinet production process represented as a chain of states

Production process components are providing transitions between states seen on figure 1 . Those components are non-automated and require different levels of automation. Modernisation goals can be described as follows:

1. Performance improvement based on the assembly process automation, including the warehouse, components hauling, electrical and mechanical installation.

2. Decreasing the overall human factor influence, including lower employee qualification requirements, smaller room for error, general improvements in ergonomic aspects.

While pursuing the aforementioned goals, the proposed modernisation program must be cost, resource and labourefficient, be environment-friendly, safe and competitive against other existing solutions.

\section{Theoretical basis}

In general sense a task of multicriteria optimisation accounting for non-linearity and uncertainty can be divided into the following stages:

1. Formulating and analysis of a goal.

2. Assignment an acceptable set of alternate routes for reaching the goal.

3. Determination of a metric in which alternate routes' effectiveness is going to be evaluated.

4. Optimisation, i.e. selection of an extreme solution (route) within the metric given.

Let's assume that for the target function $\mathrm{f}\left(\mathrm{x}_{1}, \mathrm{x}_{2}, \ldots, \mathrm{x}_{\mathrm{n}}\right)$ a set of feasible solutions $\mathrm{X}$ is given. Each solution $\mathrm{x}_{\mathrm{i}} \in \mathrm{X}, \mathrm{i}=$ $1, n$ is characterized by a tuple of heterogeneous particular criteria $\mathrm{K}=\left\langle\mathrm{k}_{\mathrm{j}}\left(\mathrm{x}_{\mathrm{i}}\right)\right\rangle, \mathrm{j}=1, m$. This means that the functional dependence $\mathrm{k}_{\mathrm{j}}\left(\mathrm{x}_{1}, \mathrm{x}_{2}, \ldots, \mathrm{x}_{\mathrm{n}}\right)=\mathrm{f}_{\mathrm{j}}\left(\mathrm{x}_{1}, \mathrm{x}_{2}, \ldots, \mathrm{x}_{\mathrm{n}}\right)$ is assumed to be known. Then the optimal solution can be written as follows:

$$
X^{o}=\arg _{x \in X} k_{j}(x)>, \forall j=1, m \text {. }
$$


A general approach to solving such problems is to regularize them, i.e. complement some new, often heuristic, information. This comes from a person - a decision maker (DM) [6], an expert, etc.

A special place among the methods of regularization is taken by the theory of utility (usefulness), the basis of which is the hypothesis of the existence on a limited set of alternatives $\mathrm{X}$ of a relative generalized quantitative assessment of their "quality" - utility $\mathrm{P}\left(\mathrm{X}_{\mathrm{i}}\right)$. From this we can conclude that if alternative solutions $\mathrm{X}_{1}, \mathrm{X}_{2} \in \mathrm{X}$ are given, and $\mathrm{X}_{1}$ is preferable to $\mathrm{X}_{2}$, then:

$$
\mathrm{X}_{1}>\mathrm{X}_{2} \Leftrightarrow \mathrm{P}\left(\mathrm{X}_{1}\right)>\mathrm{P}\left(\mathrm{X}_{2}\right.
$$

Thus, the utility $\mathrm{P}\left(\mathrm{X}_{\mathrm{i}}\right)$ is a scalar quantitative estimate that takes into account all the heterogeneous particular criteria $\mathrm{k}_{\mathrm{i}}\left(\mathrm{x}_{1}, \mathrm{x}_{2}, \ldots, \mathrm{x}_{\mathrm{n}}\right), \mathrm{i}=1^{\prime}, n$ :

$$
\mathrm{P}\left(\mathrm{X}_{\mathrm{i}}\right)=\mathrm{F}\left[\lambda, \mathrm{k}_{\mathrm{i}}\left(\mathrm{X}_{\mathrm{i}}\right)\right]
$$

where $\lambda$ is a tuple of coefficients reducing heterogeneous particular criteria to an isomorphic form. As a result, the optimal solution can be written as:

$$
X^{o}=\arg _{x \in X} \operatorname{extrF}\left[\hat{\lambda}|| \dot{k}_{i}\left(X_{i}\right)\right]
$$

where the "- "sign indicates values containing uncertainty.

Sometimes the specified uncertainty can be eliminated with the help from the decision maker and his knowledge, experience in solving and analysing such problems, etc. For example, assumptions are made about the normal law of distribution of a random variable, about the value of mathematical expectation, etc. In other cases, formalization includes the decision-maker setting the boundaries of the possible values set by a variable and a membership function that characterizes the degree of membership in a fuzzy set. Lastly, if information about the preference of values within the interval is completely absent, we will call such an uncertainty "interval".

Consider an algorithm for solving the multicriteria optimization problem taking into account nonlinearity and uncertainty for an example related to a hydraulic unit. The algorithm will be used for optimization of the "Hydraulic unit productivity" indicator which depends on such KPIs as:

- $\mathrm{X}_{1}$ - Amount of energy produced (current generation to maximum possible generation ratio);

- $\mathrm{X}_{2}$ - Hydraulic unit wear degree;

- $\mathrm{X}_{3}$ - Hydraulic unit operation time (current operating time to maximum possible operating time ratio);

- $\mathrm{X}_{4}$ - The break time duration (current time to maximum possible time ratio).

So, there is a multicriteria problem $\mathrm{f}\left(\mathrm{x}_{1}, \mathrm{x}_{2}, \mathrm{x}_{3}, \mathrm{x}_{4}\right)$, which, on the one hand, is nonlinear (the exact relation and influence of each parameter on the objective function is unknown), on the other hand, contains uncertainties (it is not always possible to accurately estimate or to predict each of the indicators $\mathrm{x}_{1}$ - $\mathrm{X}_{4}$, however, it is possible to specify interval estimates).

Consider the steps for solving the problem:

Stage 1. Formulating and analysis of the goal.

The goal is to optimize the "Hydraulic unit productivity" parameter, which depends on four KPIs $\mathrm{x}_{1}$ - $\mathrm{X}_{4}$ described above. In this case, the decision maker needs to set the degree of influence $\mathrm{a}_{1}$ - $\mathrm{a}_{4}$ of each of the parameters on the target function:

$$
f\left(x_{1}, x_{2}, x_{3}, x_{4}\right)=a_{1} * x_{1}+a_{2} * x_{2}+a_{3} * x_{3}+a_{4} * x_{4}
$$

It is known that "Amount of energy produced" and "Hydraulic unit operation time" parameters positively affect productivity, while "Hydraulic unit wear degree" and "The break time duration" worsen these parameters. Thus, the decision maker can assign the following coefficients: $a_{1}=5 ; a_{2}=-1 ; a_{3}=3 ; a_{4}=-2$, taking into account knowledge of the subject area. Then the target function will be modified:

$$
\mathrm{f}\left(\mathrm{x}_{1}, \mathrm{x}_{2}, \mathrm{x}_{3}, \mathrm{x}_{4}\right)=5 * \mathrm{x}_{1}-\mathrm{x}_{2}+3 * \mathrm{x}_{3}-2 * \mathrm{x}_{4}
$$

Stage 2. Assignment an acceptable set of alternate routes for reaching the goal.

As mentioned above, each of the parameters $\mathrm{x}_{1}-\mathrm{x}_{4}$ must have an interval estimate that eliminates the uncertainty. Then the decision maker should determine the boundaries for each of the KPIs:

$$
\mathrm{x}_{\mathrm{i}} \in\left[\mathrm{x}_{\mathrm{i} \_\min } ; \mathrm{X}_{\mathrm{i} \_\max }\right] .
$$


In our example, the factory director may put that the planned amount of energy production can vary from $70 \%$ to $110 \%$ relative to the previous amounts (the right border can exceed $100 \%$, which indicates a potentially larger generation due to, for example, the use of new equipment). Let the wear rate be in the range of 10-20\% (average for all components of the system), the operating time is $80-100 \%$ of the maximum possible, and the duration of break time is $5-10 \%$ (maintenance and possible repairs). We get:

$\mathrm{x}_{1} \in[70 ; 110], \mathrm{x}_{2} \in[10 ; 20], \mathrm{x}_{3} \in[80 ; 100], \mathrm{x}_{4} \in[5 ; 10]$.

Then we have different alternative solutions:

$$
\mathrm{X}=\left\{\mathrm{X}_{1}, \ldots, \mathrm{X}_{\mathrm{n}}\right\}, \text { где } \mathrm{X}_{\mathrm{i}}=\left\{x_{1}^{i}, x_{2}^{i}, x_{3}^{i}, x_{4}^{i}\right\}
$$

Stage 3. Determination of a metric in which alternate routes' effectiveness is going to be evaluated.

We set the criterion of optimization of the target function as a metric. In this case, we will solve the problem of finding the coefficient of maximum plant productivity depending on the interval KPIs included in it:

$$
\mathrm{f}\left(\mathrm{x}_{1}, \mathrm{x}_{2}, \mathrm{x}_{3}, \mathrm{x}_{4}\right) \rightarrow \max
$$

That is, the found solution $\mathrm{X}_{\mathrm{i}}=\left\{x_{1}^{i}, x_{2}^{i}, x_{3}^{i}, x_{4}^{i}\right\}$ will be optimal if $\mathrm{f}\left(\mathrm{X}_{\mathrm{i}}\right) \rightarrow$ max.

Stage 4. Choosing the optimal solution.

We are comparing all found solutions to find the best suited one. Table 1 has the best possible solution marked.

\begin{tabular}{|c|c|c|c|c|}
\hline $\mathbf{x}_{\mathbf{1}}$ & $\mathbf{x}_{\mathbf{2}}$ & $\mathbf{\mathbf { x } _ { 3 }}$ & $\mathbf{\mathbf { x } _ { \mathbf { 4 } }}$ & $\mathbf{f}\left(\mathbf{x}_{\mathbf{1}}, \mathbf{\mathbf { x } _ { 2 } , \mathbf { x } \mathbf { 3 } , \mathbf { x } \mathbf { 4 } )}\right.$ \\
\hline 70 & 10 & 80 & 5 & 570 \\
\hline 71 & 10 & 80 & 5 & 575 \\
\hline 72 & 10 & 80 & 5 & 580 \\
\hline 73 & 10 & 80 & 5 & 585 \\
\hline$\ldots$ & $\ldots$ & $\ldots$ & 5 & $\ldots$ \\
\hline 110 & 10 & 100 & $\ldots$ & $\ldots$ \\
\hline$\ldots$ & $\ldots$ & $\ldots$ & 9 & 812 \\
\hline 110 & 20 & 100 & 10 & 810 \\
\hline
\end{tabular}

Table 1 - Optimization results

Here hydraulic unit productivity reaches its maximum value of 830 units under the following conditions:

- Current generation to maximum possible generation ratio $\mathrm{X}_{1}=110 \%$;

- Hydraulic unit wear degree $\mathrm{x}_{2}=10 \%$;

- Current operating time to maximum possible operating time ratio $\mathrm{x}_{3}=100 \%$;

- The break time duration (current time to maximum possible time ratio) $\mathrm{X}_{4}=5 \%$.

It is also possible to evaluate the quality of the solution if the decision maker determines the utility for each solution. For example, the factory director may add the condition that a solution with the longest break times is better [11]. Then the optimal solution can be considered like $\mathrm{x}_{1}=110 \%, \mathrm{x}_{2}=10 \%, \mathrm{x}_{3}=100 \%, \mathrm{x}_{4}=10 \%$ (the last in the table) with $\mathrm{f}\left(\mathrm{x}_{1}, \mathrm{x}_{2}, \mathrm{x}_{3}, \mathrm{x}_{4}\right)=810$, because this solution is the most "useful."

\section{Proposal for a Key Performance Indicators hierarchy}

This subsection proposes a hierarchical decomposition of the power generation process. The first level of the list is divided into two following categories:

- Performance evaluation based on common indicators;

- Power generation;

The logical scheme can be implemented in the form of software that allows to display both results of the power generation process decomposition and perform calculations to optimize the process at lover level.

$\underline{\text { I General indicators }}$

1. Costs, $\$$.

1.1. Cost of equipment, $\$$. 
1.2. Costs of own staff, $\$$.

1.3. Cost of third-party specialists, $\$$.

1.4. Costs of scientific and technical research, $\$$.

1.5. Costs of computer simulation, $\$$.

2. Productivity (units may vary)

2.1. Personnel productivity.

2.2. Hydraulic unit productivity, $\mathrm{kW} * \mathrm{~h}$.

3. Efficiency (units may vary)

3.1. Investments.

3.2. Electricity efficiency, $\%$.

3.3. Staff efficiency, $\%$.

3.4. Equipment efficiency, $\%$.

3.5. Amount of investments into modeling, automation and monitoring tools, $\$$.

4. Output (units may vary)

4.1. Amount of electricity generated, $\mathrm{kW} * \mathrm{~h}$.

4.1.1. Equipment wear degree, $\%$.

4.1.2. Staff qualification level, points.

$\underline{\text { II Electricity production }}$

1. Costs, $\$$.

1.1. Personnel costs, $\$$.

1.2. Modernization costs, $\$$.

1.3. Equipment costs, $\$$.

1.4. Overcoming external conditions costs, $\$$.

1.5. Environmental protection costs, $\$$.

2. Productivity, $\mathrm{kW} * \mathrm{~h}$.

2.1. Personnel productivity, $\mathrm{kW} *$ hour.

2.1.1. Amount of electricity generated, $\mathrm{kW} * \mathrm{~h}$.

2.1.2. Number of staff.

2.1.3. Staff time, hours.

3. Efficiency, units

3.1. Electricity production efficiency, $\%$.

3.2. Stuff efficiency, $\%$.

3.3. Equipment efficiency, \%.

3.4. Amount of investments into modeling, automation and monitoring tools, $\$$.

The lists of KPIs in sections I (general indicators) and II (electricity production) share some records: it is assumed that section I relates to the operation of the hydropower plant as a whole, and section II only covers the part related to the main power producing unit.

\section{Workplace modernisation results}

Workplace modernization includes three main steps:

1. Software installation

2. Augmented Reality hardware installation

3. Assistant robot installation

Specialized software was introduced to export data from standard project files created in E3 environment [12]. Data on objects location and naming is extracted from project files using scripts, written in Python programming language. The Comtypes library is connected via the Component Object Model (COM) programming interface. Extracted data is being sent to the database, to become available for subsequent operations.

The next stage of modernization is the installation of AR equipment. The central part of the proposed hardware and software complex is a projector. Modern industrial-class projectors allow to use several colors in a projection at the same time, to integrate them into CAD systems and to provide access to the API for better customization. It can be mounted on a rigidly fixed bracket under the ceiling or on the wall, or mobile versions on a moving trolley powered by wire or accumulator batteries. 
After the data on the elements location was exported from the E3 project file using the script and the base was formed, the main cycle of work begins:

1. The assembly worker scans the marking of the wire or other component with a scanner.

2. The user terminal software identifies the element and requests its coordinates from the database.

3. The coordinates are transferred to the application core, which then passes them to the projector control software module to visualize the location of the requested element. The result can be represented as text or graphics projected over the control cabinet (see figure 2).

4. The assembly worker installs the component and connects the wires, marking the completion of the action in the user terminal.'

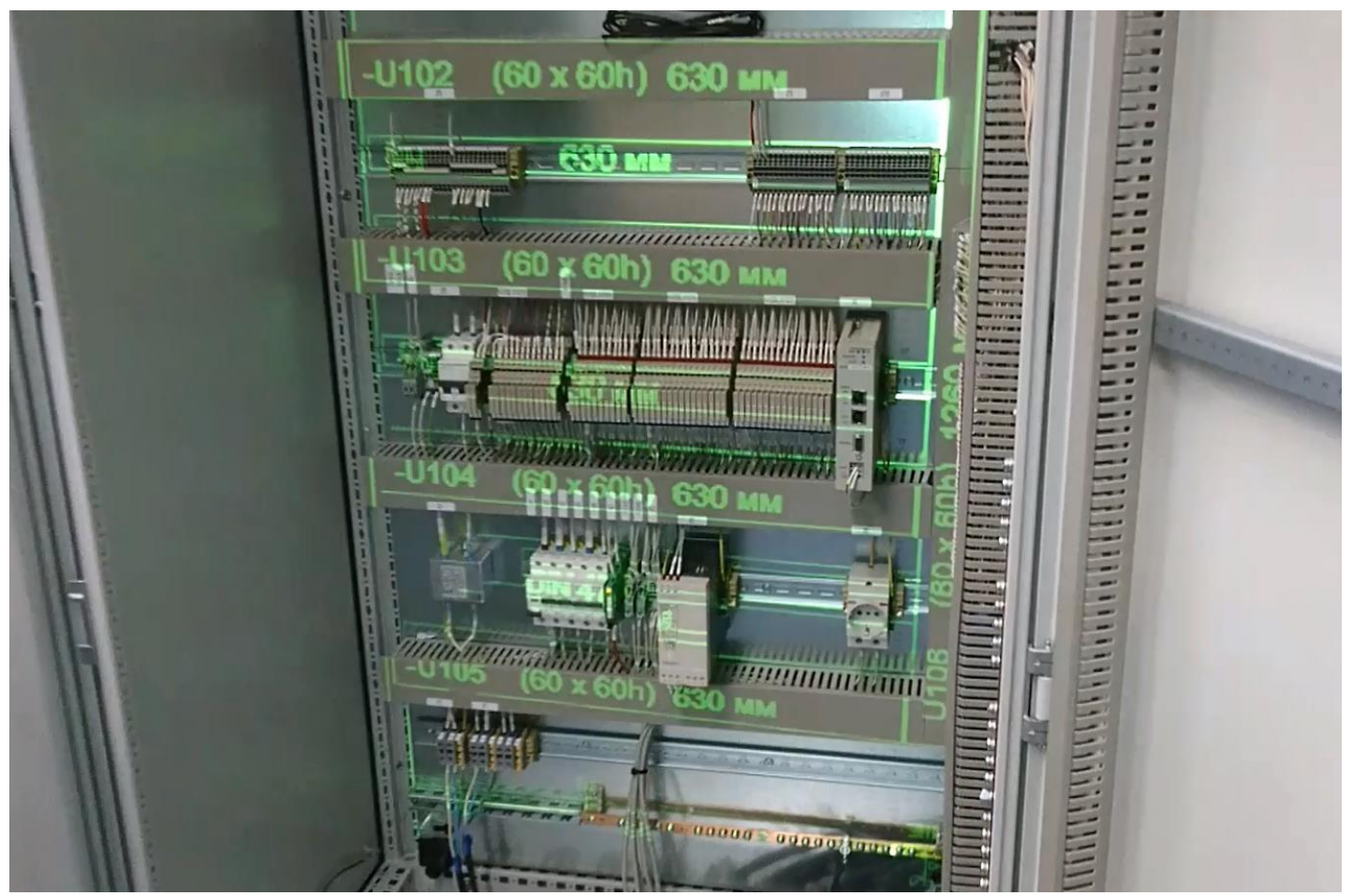

Fig. 2. Augmented reality projection

In addition to using the projector as an accompanying information tool, an assistant robot has been included into solution.

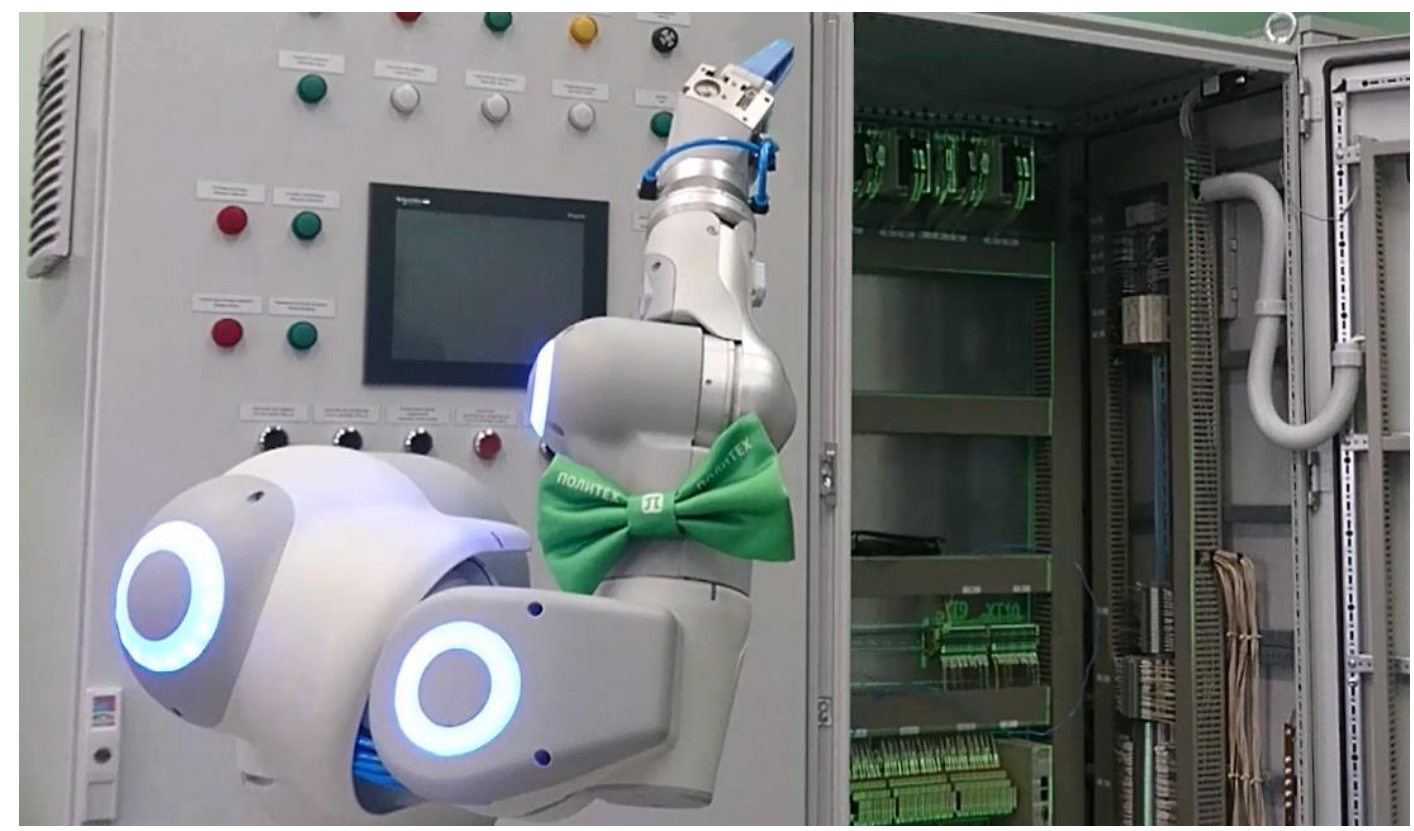

Fig. 3. Assistant robot 
The robot we used was programmed to take the required assembly part and to give it to the assembly worker, according to the information about previously scanned code.

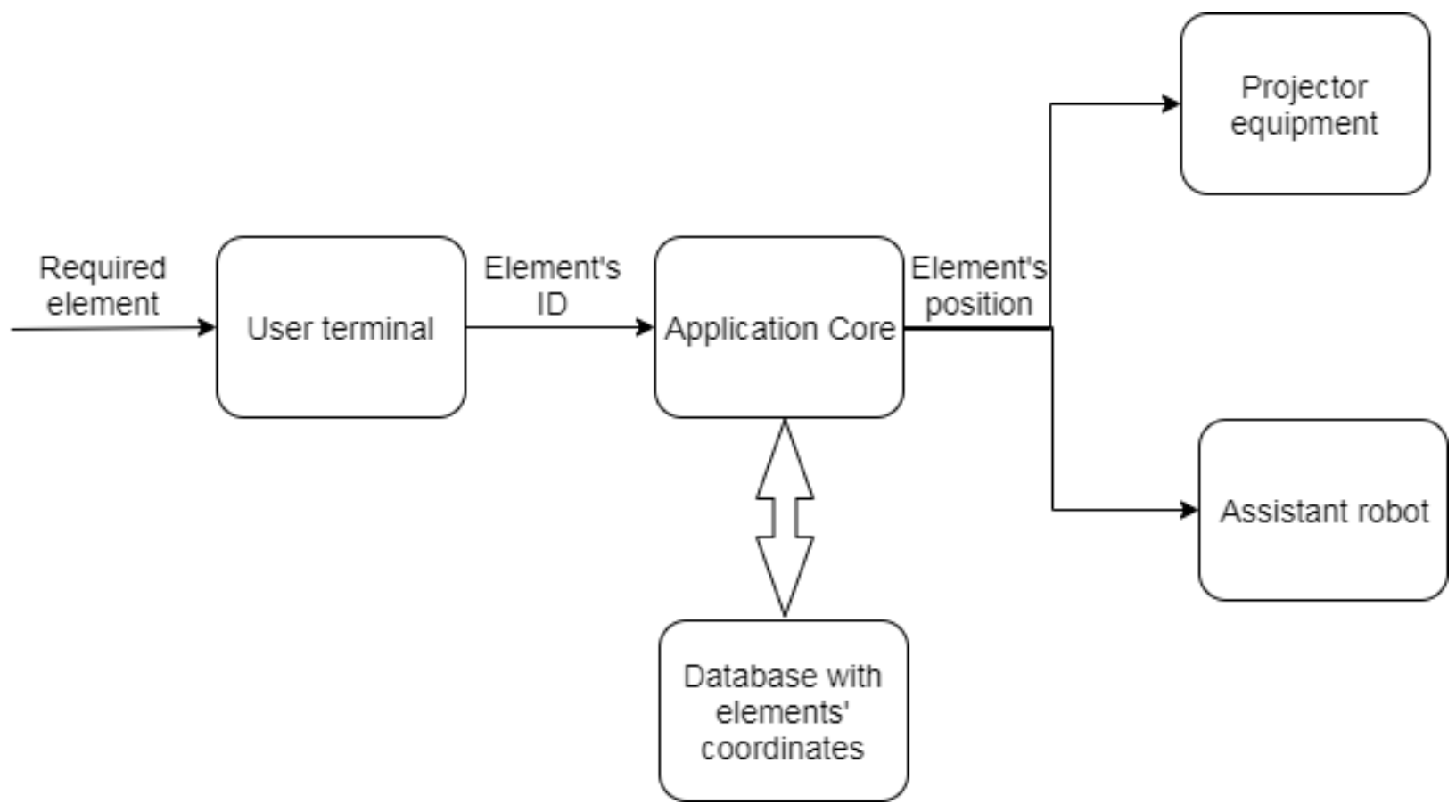

Fig. 4. Principal scheme of assistant robot's logic

As seen on figure 4, the robot uses a shared data base [13] for every piece of hardware elements, extracted directly from the E3 project file. The addition of the robot proved to be an effective time saver for an assembly worker, as it partially removed the need to switch between the control cabinet components installation to searching for them on the table [14].

Unfortunately, the robot's inability to search for components that have been moved from their pre-programmed places by accidents significantly constrained its usability. Designing a reliable, inexpensive hardware and software upgrades to the robot would be the key part of the follow-up research.

\section{Conclusion}

The control cabinet assembly process requires an assembly worker of a certain qualification, that was considered high. The nature of the process also gives the worker a significant potential in making mistakes, i.e. the human factor was considered high. Amount of time taken by the process was also a subject to contraction.

During this research the process of the control cabinet assembly was decomposed into basic states. Then a modernization program proposal was made. The program is based on the KPI hierarchy and a multicriteria optimization approach, which uses a composition of linear equations with KPIs serving as it's coefficients. The paper provides a step by step explanation of optimization method used and gives an example of it. Modernization also includes a set of hardware and software-based solutions, based on the augmented reality equipment and an assistant robot, fitted into the assembly process.

The multicriteria KPI analysis allowed for better preparation times and improved assembly components logistics. The augmented reality hardware set has simplified the assembly process by reducing the amount of decisions made by an assembly worker, thus lowering the worker qualification requirements and a potential room for errors. Inclusion of the assistant robot helped to improve the assembly time and allowed the worker to better focus on the assembly process.

The future plans include better software support and integration between the CAD systems like E3 and the assistant robot, and improving the robot's adaptive capabilities. For example, as for now the robot cannot find an item if it was moved away from its predetermined coordinates, stored in the robot's database.

\section{Acknowledgments}

The paper is published in the framework of the project Erasmus+ 573545-EPP-1-2016- 1-DE-EPPKA2-CBHE-JP and describes the part of the project conducted by Peter the Great St. Petersburg Polytechnic University. 


\section{References}

[1] Dakic, D., Stefanovic, D., Cosic, I., Lolic, T., Medojevic, M. (2018). Business Process Mining Application: A Literature Review, Proceedings of the 29th DAAAM International Symposium, pp.0866-0875, B. Katalinic (Ed.), Published by DAAAM International, ISBN 978-3-902734-20-4, ISSN 1726-9679, Vienna, Austria. DOI: 10.2507/29th.daaam.proceedings. 125

[2] Satanovaa, A., Figulia, L., Sedliacikovaa, M. (2014). Optimization of Production Process through Selected Statistical Methods, Proceedings of the 2nd Global Conference On Business, Economics, Management And Tourism, 2014, Prague, Czech Republic.

[3] Durkacova, M., Lavin, J., Karjust, K. (2012). KPI Optimization For Product Development Process, Annals of DAAAM for 2012 \& Proceedings of the 23rd International DAAAM Symposium, Volume 23, No.1, ISSN 23041382 ISBN 978-3-901509-91-9, CDROM version, Ed. B. Katalinic, Published by DAAAM International, Vienna, Austria, 2012.

[4] Lodrina, M., Kudzanayi, C., Mncedisi, T. D., Donald, M. (2014). Productivity Improvement Through Process Optimization: Case Study of a Plastic Manufacturing and Sales Company, Proceedings of the International Conference on Advances in Image processing, Computers and Industrial Engineering, Volume 1, pp. 155-161 Kuala Lumpur, Malaysia. DOI: 10.13140/2.1.3286.5283

[5] Qiang, L., Liyang, X., Jiaxin, S., Haiyang, L., Guoliang, X. (2019). Research Methods and Applications of Gear Manufacturing Process Optimization, Mathematical Problems in Engineering, vol. 2019, Article ID 7043604, 17 pages, 2019. https://doi.org/10.1155/2019/7043604.

[6] Januska, M., Faifr, A. (2017). Optimization of the In-Process Control Process Using Six Sigma Methods and Tools, Proceedings of the 28th DAAAM International Symposium, pp.0280-0288, B. Katalinic (Ed.), Published by DAAAM International, ISBN 978-3-902734-11-2, ISSN 1726-9679, Vienna, Austria DOI: 10.2507/28th.daaam.proceedings.038

[7] Kostenko, D., Kudryashov, N., Maystrishin, M., Onufriev, V., Potekhin, V., Vasiliev, A. (2018). Digital Twin Applications: Diagnostics, Optimisation and Prediction, Proceedings of the 29th DAAAM International Symposium, pp.0574-0581, B. Katalinic (Ed.), Published by DAAAM International, ISBN 978-3-902734-20-4, ISSN 1726-9679, Vienna, Austria DOI: 10.2507/29th.daaam.proceedings.083

[8] Civic, A., Vucijak A. (2013). Multi-Criteria Optimization of Insulation Options for Warmth of Buildings to Increase Energy Efficiency, Proceedings of the 24th DAAAM International Symposium on Intelligent Manufacturing and Automation.

[9] Vučijak, B, Pašić M., Zorlak, A. (2014). Use of Multi-Criteria Decision Aid Methods for Selection of the Best Alternative for the Highway Tunnel Doors, Proceedings of the 25th DAAAM International Symposium on Intelligent Manufacturing and Automation, DAAAM 2014.

[10] Evans A., France R., Lano K., Rumpe B. (1999) The UML as a Formal Modeling Notation, The Unified Modeling Language - Workshop UML'98: Beyond the Notation. Springer Verlag Berlin, LNCS 1618, DOI: 10.1007/978-3540-48480-6_26

[11] Haskovic, D., Katalinic, B., Zec, I., Kukushkin, I., Zavrazhina, A. (2017). Intelligent Adviser Module: Proposals and Adaptive Learning Capabilities, Proceedings of the 28th DAAAM International Symposium, pp.1191-1196, B. Katalinic (Ed.), Published by DAAAM International, ISBN 978-3-902734-11-2, ISSN 1726-9679, Vienna, Austria DOI: $10.2507 / 28$ th.daaam.proceedings. 165

[12] https://www.zuken.com/en/product/e3series/, (2019) Electrical, Fluid and Wire Harness Design Software. Accessed on: 2019-10-08.

[13] Kukushkin, I., Zavrazhina, A., Grabenweger, J., Katalinic, B., Haskovic, D. (2016). Simulation Approach for Analysis of the Inventory Capacity for Filling and Packaging Plants, Proceedings of the 27th DAAAM International Symposium, pp.0876-0885, B. Katalinic (Ed.), Published by DAAAM International, ISBN 978-3-902734-08-2, ISSN 1726-9679, Vienna, Austria DOI: 10.2507/27th.daaam.proceedings.126

[14] Kukushkin, I., Zavrazhina, A., Grabenweger, J., Kildibekov, A., Katalinic, B., Haskovic, D. (2016). Model-based concept for scheduling analysis of packaging lines, Proceedings of the 26th DAAAM International Symposium, pp.1149-1157, B. Katalinic (Ed.), Published by DAAAM International, ISBN 978-3-902734-07-5, ISSN 1726-9679, Vienna, Austria DOI: 10.2507/26th.daaam.proceedings.162 